\title{
ANÁLISE E IMPLANTAÇÃO DA DOMÓTICA EM EDIFíCIOS RESIDENCIAIS DE ALTO PADRÃO
}

\author{
Felipe Gustavo Demétrio' \\ Fernando Henrique Coelho Barone Furlani ${ }^{2}$ \\ Patrícia Marcondes dos Santos ${ }^{3}$
}

Resumo: A evolução da Domótica, em residências inteligentes, tem por seu objetivo determinar diretrizes de conforto. Conciliando sistemas de iluminação, liberação por biometria, sensores de perfil, piso térmico, entre outros, através de comandos centralizados. Foi desenvolvido um sistema que atinja um lado inovador na engenharia, a ponto que os construtores tenham total interesse em se adequar e transformar seus próximos projetos em métodos construtivos diferentes, agregando a partir de um ponto inicial, novas diretrizes para as inúmeras inovações que serão desenvolvidas ao longo dos próximos anos.

Palavras-chave: Tecnologia; Domótica; Integração; Conforto; Inteligência.

\footnotetext{
${ }^{1}$ Engenharia Civil/Universidade do Vale do Paraíba - UNIVAP, Brasil. E-mail: felipegdemetrio@hotmail.com.

2 Engenharia Civil/Universidade do Vale do Paraíba - UNIVAP, Brasil. E-mail: fernando.furlani@hotmail.com.

3 Engenharia Civil/Universidade do Vale do Paraíba - UNIVAP, Brasil. E-mail: patriciams@univap.br.
} 